\title{
XXIII. Secular cooling of the earth in relation to mountain-building
}

\section{T. Mellard Reade C.E. F.G.S.}

To cite this article: T. Mellard Reade C.E. F.G.S. (1887) XXIII. Secular cooling of the earth in relation to mountain-building, Philosophical Magazine Series 5, 24:147, 212-214, DOI: $10.1080 / 14786448708628080$

To link to this article: http://dx.doi.org/10.1080/14786448708628080

曲 Published online: 29 Apr 2009.

Submit your article to this journal $₫$

Џll Article views: 2

Q View related articles $₫$ 
omitted reference to the formulæ of Clausius, Van der Waals, and Sarriu. It appears to us that the relations of $a$ and $b$ in our formula to the volume is by no means so simple as that expressed by their formulæ.

XXIII. Secular Cooling of the Earth in relation to MountainBuilding. By T. Mellard Reade, C.E., F.G.S.*

TN Chapter XI. of my 'Origin of Mountain-Ranges' I 1 attempted to show that the effects of secular cooling on the earth's crust would not be that assumed by what is now called the "Contraction theory" of Mountain-formation.

But, first, it will be well to state what this theory is. Roughly speaking, then, the earth in its present state is considered to be divided into two parts; a cooled solid outer crust which does not contract, and a heated nucleus which diminishes in volume as it parts with its heat. From this it results that the hard crust, in fitting itself from time to time to the shrinking nucleus, throws up the ridges of the earth's surface called Mountain-ranges. This, in its crude form, is the theory which is usually presented to the reader.

A very little consideration will serve to show that the effects of the cooling of a body like the earth will be very much more complex.

If we assume the crust to be a hard shell, say 30 miles thick, with a temperature of $50^{\circ}$ at the outer surface, and $3050^{\circ}$ at the inner surface, we shall find that the circumferential contraction of the inner surface of the shell in cooling will be much more relatively than the radial contraction of the earth from the centre to this zone ; consequently the hard crust will at this zone be not in a state of compression, but one of tension or stretching.

By means of a diagram (plate 18) I have shown that an outer portion or shell of this hard crust, of very limited depth, will be in a state of compression; but by far the larger volume of the crust will constitute a "shell of contraction," where all the rocks constituting it will tend to stretch along circumferential lines. This stretching would end in the fracture of the shell were it not for the weight of the superimposed mass, which ensures continuity by what I have called "compressive extension."

It is unnecessary for me to go into further details as the reader can find the full particulars in the chapter referred to $\dagger$; excepting that I would point out that the external cooling portion of the earth is shown to be divisible into a thin outer

* Communicated by the Author.

$\dagger$ 'Origin of Mountain-Ranges,' pp. 121-128. 
shell - of compression greatest at the external surface, gradually diminishing downwards until it is nil at the under surface, and an inner shell of much greater volume, in which the beds are all in a state of tension by contraction, the contraction being greatest at the zone of greatest cooling, and nil on the inner and outer surfaces of the shell. Hence it follows that at the zone of contact of these imaginary shells the rock will be neither subject to tension nor compression.

Below these shells exists an uncooled nucleus, geologically speaking, of hitherto nearly constant volume.

In a recent paper* Mr. C. Davison arrives at practically the same results, although he makes no reference to my work, which was published in 1886 . If Mr. Davison reached his results without knowing of mine it strengthens my case considerably, and I am glad to have confirmation from so able a mathematician.

But while we are practically agreed as to the strains set up in the crust of a cooling carth, we entirely differ as to their geological consequences. Without committing myself to Mr. Davison's numerical results, I will for piesent purposes accept his calculation that the shell of compression is now five miles deep.

I confess I cannot follow Mr. Davison in considering that "owing to the pressure of the continental masses, cruststretching by lateral tension takes place principally beneath the ocean-basins." Assuming that the isogeotherms follow approximately the surface-contours of the land, whether beneath or above the level of the oceans, the greater pressure will be over the ocean-basins, as the weight of ocean-water will be additional to that of an equal depth of crust. It is, however, quite as probable that the cooled crust is thicker under the oceans, and such is assumed by many physicists. It also appears to me to be a physical misconception to suppose that a portion of the earth's crust would stretch like a cooling bar of iron held firmly in a vice at either end, or that the pressure of the continental masses would take the place of the vices by holding down the contracting body. I have tried to form a mental picture of the relation Mr. Davison wishes to show existing between coast-lines, earthquakes, sedimentation, and mountainbuilding, but must confess my inability to do so with the aid only of the abstract.

The statement that "the rate of mountain-making diminishes with the increase of time" is opposed to all geological fact. The greatest mountains are the youngest; and Mur-

* "On the Distribution of Strain in the Earth's Crust resulting from Secular Cooling, with special reference to the Growth of Continents and the Formation of Mountain-chains." Received by the Royal Society, April 7,1887 , and just published in abstract. 
chison even held the view that at an early period of the earth's history there were no great mountains*. We have ample grounds for believing neither view to be correct.

Prof. Bonney, in a Note appended to Mr. Davison's paper, attempts to further elucidate the geological results that would follow from this view of the effects of the earth's contraction. I am sorry that I am unable to agree with his suggestions. When $I$ wrote the chapter referred to $I$ felt, if the views there expounded were admitted (which they practically are by Messrs. Davison and Bonney), that they were futal to the Contraction-theory of Mountain-building ; I think so still.

In what way, I may ask, could gneissic axial cores, having the fan-structure which characterizes most great mountainranges, have been forced up and the overlying beds thrown back upon themselves, if the tangential compression, gradually diminishing downwards, did not extend five miles vertically into the earth's crust? for during the early periods of mountainmaking the depth of crust under compression must have been, according to Mr. Davison, much less.

For myself I go much further, and say that such axial cores and other phenomena of mountain-ranges which I have elsewhere dealt with at length, cannot be satisfactorily accounted for except on the hypothesis, within certain limits, of the compression increasing, not diminishing, with the depth.

To illustrate these effects I made a series of experiments, which are partially detailed in pp. 331-333 and plate 42 .

Although we differ radically in some important particulars, I welcome Messrs. Davison and Bonney's theoretical investigations, as truth cannot but gain by the friction of various ideas.

XXIV. On an Addition to Bunsen's Ice-Calorimeter. By C. V. BoYs, A.R.S.M., Demonstrator of Physics at the Science Schools, S. Kensington†.

TT is probable that no single instrument has excited so much 1 admiration on the part of physicists as Bunsen's calorimeter ; its beautiful simplicity, its marvellous sensibility, and its accuracy in skilled hands place it in the first rank among instruments employed in investigations for which it is available. In our uncertain climate, however, it is not often found in actual use ; for unless a large supply of perfectly pure snow, free from all saline contamination, can be obtained, it cannot be employed to its fullest advantage, and because possibly, according to Bunsen's directions, it should be uşed in a room not much above the freezing-point.

* 'Siluria,' fifth edition, p. 498.

$\dagger$ Communicated by the Author. 